\title{
A GENERAL MANAGER FOR A DENTAL CONVENTION AS ADOPTED BY THE NEW JERSEY STATE DENTAL SOCIETY.
}

\author{
By William H. Gelston, D. D. S., Camden, N. J.
}

(Read before the National Dental Association at Its Twenty-first Annual Session, New York City, N. Y, October 23-26, 1917.)

$\mathrm{T}$ HE President and Secretary of a State Dental Society are generally overworked, if that society is a hustler. The President must keep constantly in touch with the chairman of every committee for seven or eight months before that convention, to produce the results for which he is aiming. The Secretary, as we all know, has his work cut out for him from the moment he enters office, until he-resigns. From the day of the opening of that convention until the closing, that President has no time for details. He must, therefore, depend upon the chairman of the different committees, for the successful termination of that meeting. The chairman may or may not have had previous experience on that committee. If he has constructive ability he will succeed, altho he makes mistakes. If he were chairman of that committee another year, he would profit by his mistakes, but, there is another chairman the following year, and he also must learn by making mistakes; and the society pays for these mistakes, year after year.

From the beginning of time, "threes" have been paramount, and played extraordinary part in the history and welfare of the world. With all reverence, I would refer you to the Holy Trinity, the Father, Son and Holy Ghost; the three wise men of the east; the three virgins, Faith, Hope, and Charity; Hipponenes procured from Aphrodite three golden apples to win the race from
Atlanta. A drowning man goes down three times; so I might continue to refresh your memory of the threes that have made history. You will make better history for your society by having three experienced officers, a president, secretary, and manager. The manager is to the society what a manager is to the manufacturing industry. He must necessarily be a man that has had exp?rience in all phases of dental society work. He should be able to take full charge of your convention, from the procuring of your accommodations to the storage of your equipments.

It is an indisputable fact, that at conventions of all kinds, the octopus is reaching out with its tentacles, from the time it greets your goods at the railroad yards until they are again in storage, to suck in the last ha'penny the convention can produce. In an interview, some of the leading dental manufacturers stated it would be a step in retrogration if the New Jersey State Dental Society dispensed with a manager. Having satisfied ourselves by the rule of three that it is advantages to the society to procure a manager, let us first consider the duties of that office, that we may the better select the individual.

As soon as the convention city has been selected, the president, secretary and manager procure suitable headquarters, convention hall, and discounts from the hotel men's association, chamber of commerce, or whatever association 
is extending inducements for you to meet in that city. The exhibit hall having been secured, it is the duty of the manager to procure a floor plan of the hall, and lay out exhibit space. The manager having had previous experience in this as chairman of the exhibit committee, is in a position to know what the exhibitors wish in the form of exhibit space, and can plan from that standpoint, as well as the artistic. He should also plan to give the exhibitors the worth of their money, as he is building for the financial side of the convention, not only for the ensuing year but for the following years. The exhibitors at the present time state, it is noi a financial paying investment to exhibit at some of the state conventions, as their arbitrary methods of closing and opening the convention as it suited those that were in charge of the papers, or the clinics, or the election of officers, made it impossible for them to sell enough goods in the remaining time the exhibit hall was open, to pay for the heavy expense their firm was under during the convention. For years, one of the largest firms in the United States would not exhibit with the New Jersey State Dental Society, owing to arbitrary rulings. This is a financial asset that must be put on a business basis, if you expect to retain your present exhibitors and obtain new ones from year to year. At the present time, the New Jersey State Dental Society has more exhibitors than the National. It has been questioned as to whether it would not be wiser to cut out the exhibits entirely, and finance the convention from the dues of its members. From the standpoint of work and worry, it would be a great saving, but we must not overlook the fact that a great many dentists from the smaller towns and interior cities, utilize this method of obtaining dental supplies that will be the best suited to their needs, from a selection of all that is placed upon one floor by competing firms, with their most intelligent salesmen to explain the advantages of the article in which the dentists are interested.

The manager must be in the convention city a sufficient length of time in advance of the convention to make all the arrangements for the cartage of goods, hiring of laborers, carpenters, contracts for plumbing and electric wiring and watchmen, obtaining drinking water, individual cups, lumber and hardware. The building of table-tops, with floor plates and galvanized pipe legs makes an ideal way of supplying your exhibitors with tables expeditiously and permanently, which can be used from year to year, with minimum expense for storage. If a railing for individual booths is used, the manager has had this all cut and fitted long before the opening of the convention. He supervises the placing of the goods of the exhibitors at their respective booths, and thereby prevents congestion and friction in the exhibit hall. It is his duty to see that each exhibitor has the required number of outlets for gas and electric lights, as specified on his contract, and that the contract price of that space has been paid to the chairman of the exhibit committee, and as to their financial standing if it has not been paid. He must see that the exhibitors are provided with means of identification, that the general public may be excluded; oversee the placing of clinic material, and all requirements of the essayists, such as wiring, lanterns, etc.; adhering strictly to opening and closing exhibits on time. After the convention, he should tabulate and keep a record of all property of the society, and secure storage until the following convention.

Having a general outline of the duties of the manager, let us select the individual as impartially as you would select a manager for any business. $\mathrm{He}$ should, as before stated, have had expe- 
rience in the different chairmanships of dental society work. He should be a diplomat, as the handling of some exhibitors requires tact and patience; some require a firm hand, others require no handling at all and will give no trouble from year to year, if given a square deal. A manager should have had experience in the handling of men, from the laborer to the intelligent thinker; experience in contracting with plumbers, carpenters, and electricians, having a general knowledge of the cost of lumber, pipe and fittings, electric wiring, sockets, and as to the current the wires can carry, that the electrical contractor may not be able to take all of your profit. $\mathrm{He}$ must be a man who will learn by his mistakes, and be generous enough to admit them and pass the experience on to the future manager. He must have constructive ability and believe in nothing but success, and as Tid-Bits of London says:

If you think you are beaten you are;

If you think you dare not, you don't;

If you like to win but you think you can't,

It's almost certain you won't.

If you think you'll lose, you've lost;

For out of the world we find

Success begins with a fellow's will;

It's all in the state of mind.

If you think you're outclassed, you are;

You've got to think high to rise;

You've got to be sure of yourself before

You can ever win a prize.

Life's battles don't always go

To the strongest or fastest man;

But soon or late the man who wins

Is the one who thinks he can.

\section{Discussion.}

\section{Dr. Lawrence, Enid, Okla.}

This proposition of having a general manager to take charge of our conventions certainly appeals to me.

We are unconsiously drifting into this plan in our state this year. We are going to make another departure from the beaten paths in dental society work and at our next meeting we expect to divide our attendance into classes and each class will devote the full week to the study of one particular subject.

For six years we have been having lecture work almost exclusively and now we feel that we can derive more benefit from our meetings by getting down to details and training our fingers along with our minds. The idea is to have a limited number in each class and employ a competent teacher to instruct this class.

The different classes will meet together once each day for a general lecture on some subject so that the men in the different classes will receive something in addition to the special subject they are studying for the week.

You can readily see from these plans that it will require a lot of preliminary work to get the men listed in the class of their choice and secure the special teachers as well as make the detailed arrangements and here is where the general manager comes in to a good advantage.

I might incidentally state that it will cost each man in attendance at our next meeting twenty-five dollars. Sounds pretty big but we do not anticipate any trouble in getting the money.

\section{Dr. Cameron, Pennsylvania.}

I do not want you to go out with a wrong idea about what I said with regard to raising dues. It is deplorable to hear the objections raised against advancing the dues. Some local societies do not want to belong to the National Society because it increases their dues. In our society the dues are only $\$ 5$.

In ' regard to The Journal-I think that nobody ought to have The Journal who does not come into the State and National Society. It is the greatest mistake the National Society ever made to decrease its dues and then to try to get back again by adding one dollar at a 
time. They should come out and make them $\$ 10$ at once. The Association on Stomatology has $\$ 8$ dues and now has $\$ 3,000$ in the treasury and does not know how to spend it. If you will get that iron man we have heard about we will have money and we will know how to spend it.

I do not believe in asking exhibitors to come and exhibit their goods. We give them the opportunity and it is something for which they ought to pay. I had an experience in Pennsylvania with the exhibitors. During the hours when they had expected to have the exhibit open a scientific meeting was to be held in the balcony and it would have been impossible to hold both at the same time.

It was expected that the exhibits should be closed during the meeting but it was not understood that this meeting was to be held so early in the morning. I did not know that the meeting would be held at 9 o'clock in the morning until 11:30 the night before. When I reached the place the exhibitors were wrangling. There was a great disturbance because the door was closed and locked as I had ordered it to be. The exhibitors had expected to exhibit until 10 o'clock and were very angry. I would not give in to them and allow them to interfere with the meeting. This may now have been perfectly fair but I wanted it definitely understood that the exhibit must not interfere with our meetings.

\section{Dr. Gelston, New Jersey: I think} Dr. Cameron was a little too severe in his ruling closing the exhibits as he has stated. These firms are under a heavy expense exhibiting at our societies, and I can see no good reason why the exhibits should not be open all day, and every day of the convention. If it interferes with your clinics, that is the fault of your clinic or exhibit committee or both; but certainly the exhibitor is entitled to the space for which he pays for the entire time of the convention. Some exhibitors have informed me that some societies show a great deal of discrimination between exhibitors in assigning space. We have very little trouble on that line. All letters containing blueprints, contract, etc., are timed so that the exhibitor in Chicago will receive his Monday morning, those in Pittsburgh, Monday morning, and those right here in New York or Philadelphia, Monday morning. In that letter we tell them their selections will be assigned in the order received either by telephone, telegraph, or letter; and if by telephone or telegraph, signed contracts must immediately follow by mail, with check for half the amount of space reserved. We also ask them to make second and third choices if selecting by mail, so that if first choice has been secured by some firm acting quicker, they can immediately have the next best. With this method we have very little trouble with our exhibitors. Dr. Lawrence spoke of paying a general manager, so that the society could feel that they had the right to expect certain things of him. I will just state that the New Jersey society pays its manager.

Dr. Cameron: I know we did not do right in excluding those exhibitors. Our chairman had done wrong in making the arrangements. 'The question simply was whether we would allow those exhibitors to spoil our clinic or not and I did not believe in letting them do that.

Dr. Jones, New Jersey: I think we should try where possible to raise the salaries of the state secretaries, for the office of state secretary entails an immense amount of work and the secretary deserves a liberal salary. It seems to me that this Section should go on record as recommending a liberal salary for the state secretaries.

Dr. Lawrence: Now there are only about 20 per cent. of the societies paying 
their secretaries anything. Some of the societies pay their secretary as little as $\$ 25$, as Dr. King has brought out in his report.

Dr. Kennedy: Ought we not pay the district superintendents somathing also? that.

Dr. Lawrence: I do not approve of

Dr. Casto, Ohio: I believe that one of the most important offices to be considered in state societies is that of Executive Secretary. The business involved in handling most state societies has become quite a proposition, and can easily be neglected if it has to be put into the hands of a new committee each year. I think that an Executive Secretary who could look after all the business of the Society, including the exhibits in connection with and under the supervision of the officers and proper committees, would be of a distinct advantage and would result in greater efficiency. In Ohio a committee has been appointed to work out the proposition of installing such an office, and they hope to present the matter in concrete form that it may be considered and acted upon at the annual meeting of the society which is to be held in December.

Dr. Van Horn, Pennsylvania: Dr. Cameron has expressed regret that he did not see any representatives from Pennsylvania. I am from Pennsylvania. I understood that we were to have this program at $1: 30$ this afternoon. This is the most important session we are having from my point of view and I certainly did not want to miss it. I now understand that you have had the afternoon program this morning. I would like to know how we are to find out when and where we are to come when such changes are made in the program. We were to have had only the business session this morning. Why are these changes made in the program?
Dr. Forsyth: 'The change in the program was announced at the meeting last night.

Dr. Van Horn: I think it most un' wise to change the program-by an' nouncement- of the National meetings. Men travel many miles for enlightenment; they have noted in the program the most desirable features available and have set apart the specified time. Changing the time fixed for those features is quite disappointing and a bit discouraging.

Dr. Luthringer, Illinois: I went to commend this idea of Dr. Gelston's of having a general manager for a convention, also I wish to speak of the work of the state secretary. When the work warrants it, provision should be made for the state secretary to have an assistant. This would cost from $\$ 300$ to $\$ 600$ a year depending upon the amount of work of the offics. Where it does not require too much time his regular office assistant could take care of this work. Now we have a separate secretary's office with about ten by twelve feet of floor space. It is furnished with a desk, shelves, fire-proof vault, addressograph, etc. The assistant secretary need not nccessarily be a stenogfapher for it is a very easy matter to install a dictaphone which will enable ybu to take care of letters after office hours, that is those that are not urgent. In many cases the secretary is also the editor of the monthly Bulletin. If you happen to be the editor of your publication you know the work that means. I happen to have a very efficient assistant who relieves me of the greater part of the routine work of the office.

I wish to make a motion. I move that this section put itself on record as advocating that each state society pay its secretary a salary.

The motion was seconded and carried. 